\title{
The symptomatology of climacteric syndrome: whether associated with the physical factors or psychological disorder in perimenopausal/postmenopausal patients with anxiety-depression disorder
}

\author{
Borong Zhou $\cdot$ Xiaofang Sun $\cdot$ Ming Zhang $\cdot$ \\ Yanhua Deng · Jiajia Hu
}

Received: 5 August 2011 / Accepted: 15 November 2011 / Published online: 29 November 2011

(C) The Author(s) 2011. This article is published with open access at Springerlink.com

\begin{abstract}
Purpose To explore whether the symptoms of climacteric syndrome associated with its physical factors or psychological disorder in perimenopausal/postmenopausal patients with anxiety-depression disorder.

Methods We recruited 78 climacteric patients with anxiety-depression disorder and 72 control participants in perimenopausal/postmenopausal without anxiety-depression disorder for this study. We measured symptoms using the Greene Climacteric Symptom Scale in all cases. We also collected demographic data and tested sexual hormone, blood pressure, bone density, cognitive, estrogen receptoralpha $(\mathrm{ER} \alpha)$ gene polymorphism as physiological factors, using HARS-14 and CHDS assessed psychological disorder degree.

Results C-MMSE scores as well as Estradiol and progesterone levels in the anxiety-depression disorder group were significantly lower compared to the control group $(P<0.01)$. In addition, the anxiety-depression disorder group had significantly higher Greene Climacteric Scale scores, as well as somatic symptoms compared to controls
\end{abstract}

B. Zhou $(\varangle) \cdot$ Y. Deng $\cdot$ J. Hu

Department of Neurology,

The Third Affiliated Hospital of Guangzhou Medical College,

Guangzhou 510150, China

e-mail: Zhoubr8@yahoo.com.cn

X. Sun

Research Institute of Gynecology and Obstetrics,

The Third Affiliated Hospital of Guangzhou Medical College, Guangzhou 510150, China

M. Zhang

Department of Epidemics and Health Statistics,

Guangdong Pharmacy College, Guangzhou 510240, China
$(P<0.01)$. Moreover, the anxiety, depression and somatic symptoms of the Greene Climacteric Scale were positively correlated with HARS-14 and CHDS scores $(P<0.001)$ and negatively with estrogen level and C-MMSE scores $(P<0.05)$ in the anxiety-depression disorder group. Greene Climacteric Scale Symptoms were not significantly correlated with blood pressure, bone density or other factors $(P>0.05)$. There was no significant change in the allele frequency or the estrogen receptor-alpha gene polymorphisms, between the two groups $(P>0.05)$; however, the Pp genotype was negatively associated with C-MMSE scores ( $r=$ appraises, $P=0.033$ ).

Limitations The sample size was relatively small.

Conclusions The symptoms of somatic symptoms in patients with climacteric syndrome and anxiety-depression disorder are associated with the emotional disorder but not with a physical disease. The Pp ER $\alpha$ polymorphism Pvu II is associated with a cognitive decrease.

Keywords Climacteric $\cdot$ Anxiety-depression - Somatic symptoms $\cdot$ Cognitive $\cdot$ Physical disease

\section{Introduction}

Women in perimenopausal or postmenopausal, with the gradual degradation of ovarian function in the female hormone decreasing, can appear some physiological and psychological aspects of symptoms, main performance: hot, sweaty, tired, headache, dizziness, numb, sore limbs, attention poor, anxious and nervous, insomnia, mood swings, and sorrow depression, clinical called "menopause syndrome" or "climacteric syndrome" [1,2]. Depression or anxiety or depression combined anxiety (anxiety-depression) is a common psychological disorder in menopausal women. In 
SWAN $2010,18 \%$ of elderly women had psychological disorders [3], and anxiety-depression in addition to have major depression, dropping interest, outside self-evaluation, anxiety, nervousness, tendency to get angry, and also may be associated with fatigue, insomnia, inattention, memory loss, pain and so on menopause syndrome-like symptoms. Two diseases have common some syndromes characteristic (especial somatic syndrome) easily confused in clinic, but also have difference risk for healthy. Although emotional disorders occur frequently in climacteric syndrome, climacteric syndrome that severely compromises life and work is rare. In contrast, anxiety-depression disorder has serious risk for women [4]. On the other hand, decline in the health of patients (e.g., hypertension and osteoporosis) often accompanies mild cognitive dysfunctions $[5,18,20]$. Some patients are excessively concerned about their health and visit clinics frequently, which can lead to many misdiagnoses and waste medical resources $[6,7]$. Do these patients have multisystem symptoms resulted from somatized anxiety-depression disorder or from truly organic diseases?

Reports on syndromes characteristic patients with anxiety-depression disorder in perimenopausal are limited. Are the multisystem symptoms of patients with anxiety-depression disorder in perimenopausal/postmenopausal as severe as their psychological ones? This question needs to be investigated further. Estrogen receptor (ER) polymorphisms are associated with many disorders including Alzheimer's disease (AD), osteoporosis and coronary heart disease [8-11]; however, little is known about the association between ER polymorphisms and anxiety-depression comorbid with climacteric syndrome. In this study, we analyzed ER polymorphisms, sex hormone levels, psychological symptoms, cognitive function, blood pressure, bone density, menopausal transition (MT) stages and diseases course based on the Greene Climacteric Scale categories [12]. This study would be to recognise syndromes characteristic and provide the theoretical base for the early diagnosis of depression or anxiety in perimenopausal/ postmenopausal.

\section{Methods}

Participants and sampling

Based on our study aim and requirements for statistical analyses, between 2007 and 2010, we recruited over 78 patients with anxiety and depression in perimenopausal and postmenopausal, as well as control participants with climacteric syndrome only. Concerning menopausal status we used the following definitions: perimenopausal women having irregular menses, less than 12 menses during the last 12 months and postmenopausal: no more menses in the last
12 months. All participants meet the Stages of Reproductive Aging Workshop (STRAW) criteria for peri/postmenopause, MT score of STRAW be -1 to +2 [2], combined with at least one symptom of climacteric syndrome. The age range of this sample was 40-60 years old. Exclusion criteria of All participants undergoing hormonal therapy, hormone therapy by implant in the preceding 6 months, endocrinopathies leading to menstrual irregularities, hepatopathies, thrombopathies, use of drugs which interfere in the menstrual cycle, anxiolytics and antidepressants (as their use indicates previous diagnosis of mood disorders), hysterectomy, oophorectomy, cancer or psychiatric disease or other severely organic diseases. This study was approved by the institutional review board of the Third Affiliated Hospital of Guangzhou Medical College (Guangzhou, China) and written informed consent was obtained from every participant.

We placed participants in the anxiety-depression group using the anxiety and depression diagnosis standard listed in ICD-10 [13]. The criteria include the following: (1) use of the Hamilton Anxiety Rating Scale-14 items (HARS-14) $[14,15]$ and the Chinese version of the 17-item Hamilton Depression Rating Scale (CHDS) [16], all patients HARS14 scores $\geq 14$ and or CHDS $\geq 17$; (2) experience of major anxiety symptoms for at least 3 months or major depression symptoms for at least 2 weeks; and (3) decline in functioning at work and home. Using these standards, we recruited 78 patients with major anxiety and or depression symptoms as anxiety-depression group, of whom 58 had mixed anxiety and depression disease(MADD, ICD-10 code F41.2), 13 of whom had anxiety only (ICD-10 code F41.8) and 7 of whom had depression only (ICD-10 code F32.0). The average age of these patients was $52.14 \pm 5.74$ years. Although somatization disorder is a somatoform disorder that overlaps with a number of functional somatic syndromes and has high comorbidity with major depression and anxiety disorders [17]. The study anxiety-depression patients were not coincided with somatization or somatization form disorder diagnosis criterion (ICD-10 code F45.0, F45.1).

\section{Procedure}

We recorded patient demographic information including age, education, disease course and menopausal status. Education level was defined as time spent in school. Disease course was defined as the duration of their symptoms in years; a disease course of over 6 months was considered to be 1 year. Menopause was defined as the cessation of menses for over 12 months according to SRTAW [2]. The early postmenopausal cases was $26(33.33 \%)$ and $28(38.89 \%)$ in anxietydepression group and control group. There were no difference between them $(P<0.01)$. We used the HARS-14 and CHDS to determine anxiety and depression levels [14-16]. 
Table 1 Greene Climacteric Scale score comparisons between the anxiety-depression group and the control group $(x \pm s)$
Using a Chi-square test ${ }^{\mathrm{a}} P<0.01,{ }^{\mathrm{b}} P<0.05$

\begin{tabular}{lll}
\hline Groups & $\begin{array}{l}\text { Anxiety-depression } \\
\text { group }(n=78)\end{array}$ & $\begin{array}{l}\text { Control } \\
\text { group }(n=72)\end{array}$ \\
\hline 1. Heart beating quickly or strong & $1.14 \pm 0.78^{\mathrm{a}}$ & $0.56 \pm 0.6$ \\
2. Feeling tense or nervous & $1.42 \pm 0.86^{\mathrm{a}}$ & $0.63 \pm 0.54$ \\
3. Difficulty in sleeping & $1.33 \pm 0.81^{\mathrm{a}}$ & $0.58 \pm 0.65$ \\
4. Excitable & $1.31 \pm 0.86^{\mathrm{a}}$ & $0.37 \pm 0.47$ \\
5. Attacks of panic & $0.74 \pm 0.82^{\mathrm{a}}$ & $0.21 \pm 0.35$ \\
6. Difficulty in concentrating & $1.11 \pm 0.81^{\mathrm{a}}$ & $1.02 \pm 0.62$ \\
7. Feeling tired or lacking in energy & $1.56 \pm 0.83^{\mathrm{a}}$ & $0.38 \pm 0.4$ \\
8. Loss of interest in most things & $1.05 \pm 0.90^{\mathrm{a}}$ & $0.25 \pm 0.32$ \\
9. Feeling unhappy or distressed & $1.20 \pm 0.86^{\mathrm{b}}$ & $0.86 \pm 0.51$ \\
10. Crying spells & $0.85 \pm 0.90^{\mathrm{a}}$ & $0.18 \pm 0.36$ \\
11. Irritability & $1.32 \pm 0.93^{\mathrm{a}}$ & $0.47 \pm 0.5$ \\
12. Feeing dizzy or faint & $1.42 \pm 0.99^{\mathrm{a}}$ & $0.52 \pm 0.38$ \\
13. Pressure or tightness in head or body & $1.23 \pm 0.89^{\mathrm{a}}$ & $0.25 \pm 0.31$ \\
14. Parts of body feel numb or tingling & $1.21 \pm 0.85^{\mathrm{a}}$ & $0.52 \pm 0.45$ \\
15. Headaches & $1.41 \pm 0.91^{\mathrm{a}}$ & $0.98 \pm 0.62$ \\
16. Muscle and joint pains & $1.27 \pm 0.92^{\mathrm{a}}$ & $0.85 \pm 0.49$ \\
17. Loss of feeling in hands or feet & $0.44 \pm 0.70^{\mathrm{a}}$ & $0.24 \pm 0.34$ \\
18. Breathing difficulties & $0.59 \pm 0.76^{\mathrm{a}}$ & $0.18 \pm 0.27$ \\
19. Hot flashes & $0.85 \pm 0.88^{\mathrm{b}}$ & $1.29 \pm 0.91$ \\
20. Sweating at night & $0.74 \pm 0.77^{\mathrm{b}}$ & $1.06 \pm 0.81$ \\
21. Loss of interest in sex & $0.85 \pm 0.88$ & $0.78 \pm 0.61$ \\
\hline
\end{tabular}

\section{The Greene Climacteric Scale}

We analyzed the characteristics of climacteric syndrome based on the Greene Climacteric Scale. In 2010, the validation and reliability of Greene Climacteric Scales (validation 0.68-0.76, reliability $0.83-0.87$ in Chinese population) was reported by Zheng et al. in HongKang. The Greene Climateric Scale measures a total of 21 symptoms (Table 1) $[12,18]$. Each symptom is rated by the woman herself according to its current severity using a four-point rating scale: not-at-all symptoms (0); a little symptoms (1); quite a bit symptoms (2); extreme symptoms (3). The Greene Climacteric Scale scores include 21 items scores and an individual score within five symptom clusters: (1) anxiety symptoms (symptoms 1-6), (2) depression symptoms (symptoms 7-11), (3) somatic symptoms (symptoms 12-18), (4) vasomotor symptoms (symptoms 19-20) and (5) sexual function (symptoms 21). The mean score for each symptom is calculated by the sum of all individual scores divided by the number of subjects. The mean score of each symptom clusters are the mean scores of the symptoms within that cluster.

The organic diseases diagnosis was based on the 2007 ESH-ESC (European Society of Hypertension-European Society of Cardiology) Practice Guidelines [19], the 2009 Osteoporosis Guidelines [20, 21] and the standard for early detection of dementia, including mild cognitive impairment
[22], blood pressure, poor recognition ability and low bone density. Our study used the Chinese Mini Mental State Examination (C-MMSE) [23, 24] to assess the patient recognition function and the Fan Beam X-ray Bone Densitometer to assess bone density. We measured real-time blood pressure over $24 \mathrm{~h}$ to calculate patients' average systolic and diastolic measurements.

\section{Sexual hormone determination}

We measured estradiol (E2), progesterone and testosterone levels using radioactive immunoassays. Peripheral vein blood was collected between 7:00 and 8:00 am. Blood from non-menopausal women were collected 3 days after their menstrual cycles. The variation of estradiol, progesterone and testosterone levels within anyone group was 5.6, 7.2 and $8.01 \%$, respectively. The differences of estradiol, progesterone and testosterone levels between the groups were $6.5,7.8$ and $8.5 \%$, respectively. The sensitivity of each ELISA assay was $0.01,0.001$ and $0.0001 \mathrm{pg} / \mathrm{ml}$, respectively.

The analysis of polymorphisms in ER $\alpha$ genes, PvuII and XbaI primer design and synthesis

The sequence for the estrogen receptors is as follows: P1: 5'-CTGCCACCCTATCTGTATCTTTTCCTATTCTCC-3'; 
and P2: 5'-TCTTTCTCTGCCACCCTGGCGTCGATTAT CTGA- $3^{\prime}$. In descending order, the DNA molecular weight (Mark Shenzhen, Yishengtang Biological Enterprises Ltd.) of these receptors are 2,000 bp/1,600 bp/1,200 bp/800 bp/ $600 \mathrm{bp} / 400 \mathrm{bp} / 200 \mathrm{bp}$.

The method for genotyping estrogen receptors uses three steps. (1) Whole genomic DNA was extracted using the fast extraction method. (2) A polymerase chain reaction (PCR) where the total reaction estrogen receptor volume was $50 \mu \mathrm{L}$ and comprised $34.3 \mu \mathrm{L}$ sterile deionized water, $5 \mu \mathrm{L}$ $10 \times$ PCR buffer, $200 \mu \mathrm{mol} / \mathrm{L}$ dNTP $4 \mu \mathrm{L}, 40$ pmol primers, 100 ng DNA template and 1 U TaqDNA polymerase. Reaction conditions consisted of a denature step at $94^{\circ} \mathrm{C}$ for $3 \mathrm{~min}$, followed by 35 cycles of $94^{\circ} \mathrm{C}$ for $30 \mathrm{~s}, 61^{\circ} \mathrm{C}$ for $40 \mathrm{~s}, 72^{\circ} \mathrm{C}$ for $90 \mathrm{~s}$, and a final extension at $72^{\circ} \mathrm{C}$ for $5 \mathrm{~min}$. The extension product size was $1.3 \mathrm{~kb}$. (3) Finally, a restricted enzymatic reaction was performed using $6 \mathrm{U}$ PvuII and $10 \mathrm{U}$ XbaI for enzymatic digestion, followed by a 1.2 agarose gel with ethidium bromide electrophoresis for $40 \mathrm{~min}$, which was then photographed.

Two professional psychologists tested patients' neurological and psychological statuses. Prior to these tests, both psychologists were trained to adjust and unify their standards.

\section{Statistical analysis}

All data were recorded as mean \pm standard deviation $(x \pm s)$. We used SPSS 17.0 software for all statistical analyses. (1) ANOVA and ANCOVA rank-sum tests (i.e., variance arrhythmias) analyzed the demographic and symptomatic differences between the anxiety-depression group and the control group. (2) Pearson's correlation analyzed the relationships between symptoms, psychological scores and physiological status. (3) Chi-square tests analyzed the frequency of estrogen receptor-alpha polymorphisms. (4) Multifactorial logistic analyses analyzed the relationship between the ER $\alpha$ polymorphism and other symptoms such as sex hormone levels, psychological scores (HARS-14 and CHDS) and cognitive functions. A $P$ value of less than 0.05 was considered significantly different.

\section{Results}

Differences in demographic information, HARS-14, CHDS, C-MMSE, Greene Climacteric Scale scores and sexual hormone levels between groups

As shown in Table 1, there were significant differences between the anxiety-depression group and the control group $(P<0.001)$ in all areas except difficulty in concen- trating and sexual interest. The vasomotor symptoms scores as well as the facial redness and evening sweating scores for the anxiety-depression group were significantly lower $(P<0.05)$ compared to the control group; all other anxietydepression group scores were higher than the control group $(P<0.01)$. As shown in Table 2 , the Greene climacteric Scale scores of anxiety, depression and somatic symptoms were significantly higher in the anxiety-depression group $(P<0.001)$ compared to control group, although the vasomotor symptoms scores were significantly lower $(P<0.05)$. The HARS-14 and CHDS scores of the anxietydepression group were significantly higher than the control group $(P<0.001)$ whereas the $\mathrm{E} 2$ and progesterone levels were significantly lower $(P<0.001)$. The cut-off score for the statistics in Table 2 is 27 (mild cognitive difficulty [21]. An ANCOVA rank sum test (variance arrhythmias) showed that the C-MMSE score in the anxiety-depression group was significantly lower than the control group $(P<0.01)$. There were no significant differences in age, testosterone level, bone density, systolic and diastolic blood pressure between the two groups.

Correlation analysis between Greene Climacteric Scale symptoms with general condition, psychological score, bone density, average blood pressure in anxiety-depression disorder group

As shown in Table 3, Pearson's correlational analyses, revealed positive correlations between Greene Climacteric Scale anxiety, depression and somatic symptoms scores with HARS-14 and CHDS scores $(P<0.001)$ as well as negative correlations between E2 and progesterone levels and C-MMSE scores $(P<0.05)$ within the anxiety-depression group. There was also a positive correlation between education years in the anxiety-depression group. There was an additional correlation between vasomotor symptoms and HARS-14 scores, whereas sexual factors were correlated with CHDS scores $(P<0.05)$. There was no significant correlation between Greene Climacteric Scale scores and blood pressure, bone density, menopause, disease course or other factors $(P>0.05)$.

Polymorphism analyses on the ER $\alpha$ gene

We used $\mathrm{P}, \mathrm{pX}$ or $\mathrm{x}$ to indicate restriction enzymes. Lowercase letters indicated the digestion sites of the enzyme, whereas capital letters indicated the absence of restricted enzyme sites. The PvuII restriction enzyme distinguishes between three genotypes: PP $(1.3 \mathrm{~kb}), \quad \mathrm{Pp}(1.3 \mathrm{~kb}+$ $850 \mathrm{bp}+450 \mathrm{bp})$ and pp $(850 \mathrm{bp}+450 \mathrm{bp})$. The XbaI restriction enzyme distinguishes between three genotypes: $\mathrm{XX} \quad(1.3 \mathrm{~kb}), \quad \mathrm{Xx} \quad(1.3 \mathrm{~kb}+910 \mathrm{bp}+390 \mathrm{bp})$, and $\mathrm{xx}$ (910 bp + 390 bp; Fig. 1) 
Table 2 Comparison of Greene Climacteric Scale, HARS-14, CHDS, and C-MMSE scores, as well as sexual hormone levels, bone density and average blood pressure $(x \pm s)$
Using a Chi-square test, ${ }^{\mathrm{a}} P<0.01,{ }^{\mathrm{b}} P<0.05$

\begin{tabular}{lccc}
\hline Groups & $\begin{array}{c}\text { Anxiety-depression } \\
\text { group }(n=78)\end{array}$ & $\begin{array}{l}\text { Control } \\
\text { group }(n=72)\end{array}$ & $P$ value \\
\hline Age (years) & $52.14 \pm 5.74$ & $51.55 \pm 4.87$ & 0.576 \\
Education (years) & $8.95 \pm 2.63^{\mathrm{b}}$ & $10.57 \pm 3.67$ & 0.010 \\
Disease time of anxiety and & $4.18 \pm 3.41$ & 0 & $/$ \\
$\quad$ depression (years) & & & \\
HARS-14 score & $16.42 \pm 9.32^{\mathrm{a}}$ & $5.54 \pm 2.73$ & 0.000 \\
CHDS score & $15.4 \pm 8.02^{\mathrm{a}}$ & $4.6 \pm 1.86$ & 0.000 \\
C-MMSE score & $26.97 \pm 1.88^{\mathrm{a}}$ & $28.92 \pm 0.72$ & 0.000 \\
E2 (pg/ml) & $133.63 \pm 161.32^{\mathrm{a}}$ & $304.83 \pm 248.64$ & 0.000 \\
Testosterone (pg/ml) & $0.89 \pm 0.33$ & $1.12 \pm 0.21$ & 0.143 \\
Progesterone (pg/ml) & $4.68 \pm 10.08^{\mathrm{a}}$ & $15.34 \pm 27.00$ & 0.000 \\
Whole body bone density & $1.022 \pm 0.119$ & $1.024 \pm 0.109$ & 0.738 \\
BlAv Mean systolic pressure (mmHg) & $140.94 \pm 21.59$ & $138.48 \pm 15.29$ & 0.681 \\
Average diastolic pressure (mmHg) & $80.78 \pm 13.65$ & $78.96 \pm 10.81$ & 0.127 \\
Anxiety symptoms & $1.19 \pm 0.52^{\mathrm{a}}$ & $0.56 \pm 0.35$ & 0.000 \\
Depression symptoms & $1.21 \pm 0.61^{\mathrm{a}}$ & $0.41 \pm 0.37$ & 0.000 \\
Somatic symptoms & $1.09 \pm 0.54^{\mathrm{a}}$ & $0.57 \pm 0.59$ & 0.000 \\
Vasomotor symptoms & $0.83 \pm 0.70^{\mathrm{b}}$ & $1.12 \pm 0.84$ & 0.025 \\
Sexual function symptoms & $0.85 \pm 0.89$ & $0.78 \pm 0.61$ & 0.452 \\
\hline
\end{tabular}

Table 3 Correlation analysis between the Greene Climacteric Scale symptoms with general condition, psychological score, bone density and average blood pressure in anxiety-depression disorder group

\begin{tabular}{lcl}
\hline Variations & & \\
\hline Correlation factors & Co-efficient & $P$ value \\
\hline Anxiety symptoms & & \\
Education years & 0.235 & 0.039 \\
E2 & -0.371 & 0.001 \\
Progesterone & -0.310 & 0.007 \\
HARS-14 & 0.795 & 0.0001 \\
CHDS & 0.791 & 0.0001 \\
C-MMSE & -0.343 & 0.002 \\
Depression symptoms & & \\
E2 & -0.249 & 0.028 \\
HARS-14 & 0.560 & 0.0001 \\
CHDS & 0.613 & 0.0001 \\
C-MMSE & -0.242 & 0.033 \\
Somatic symptoms & & \\
E2 & -0.325 & 0.004 \\
HARS-14 & 0.639 & 0.0001 \\
CHDS & 0.711 & 0.0001 \\
C-MMSE & -0.380 & 0.001 \\
Vasomotor symptoms & & 0.020 \\
HARS-14 & 0.227 & \\
Sexual factors & & \\
CHDS & 0.262 & \\
\hline
\end{tabular}

ER gene polymorphisms and the allele frequency distribution

Table 4 shows the allele frequency of the ER $\alpha$ Pvu II and Xba polymorphisms. The allele frequencies of the studied sample were consistent with the Hardy-Weinberg Genetic equations and representative populations. The genotype distribution in the anxiety-depression group was PP17.95\%, Pp39.74\%, pp42.31\%, XX10.26\%, Xx32.50\% and $\mathrm{x} \times 57.69 \%$. The allele frequency for $\mathrm{P}$ and $\mathrm{X}$ is 37.81 and $26.28 \%$, respectively. Both groups have a majority of $p$ and $x$ gene sites. As shown in Table 4, there were no significant differences between the anxiety-depression and control groups in the genotypes of the ER $\alpha$ PvuII or Xba I polymorphisms.

The correlation between ER gene polymorphisms and anxiety-depression symptoms

One-way factorial analyses indicated that the Pp and $\mathrm{pp}$ genotypes were correlated with anxiety, depression, and organic diseases, as well as CHDS, HARS-14 and C-MMSE scores. The xx genotype was correlated only with organic disease and vasomotor symptoms. When we introduced the ten factors above into a multifactorial logistic model, only the Pp genotype and C-MMSE scores were negatively correlated $(\mathrm{y}=4.51 \times 1.043-2.22, r=-0.108$, $95 \%$ CI $0.014 \sim 0.883, P=0.033)$. 
Fig. 1 Left the endonuclease PvuII distinguished three genotypes: PP $(1.3 \mathrm{~kb}), \mathrm{pp}$ $(850 \mathrm{bp}+450 \mathrm{bp})$ and $\mathrm{Pp}$ $(1.3 \mathrm{~kb}+850 \mathrm{bp}+450 \mathrm{bp})$. Right the Endonuclease Xba I gene distinguished three genotypes: $\mathrm{Xx}$ $(1.3 \mathrm{~kb}+910 \mathrm{bp}+390 \mathrm{bp})$ $\mathrm{xx}(910 \mathrm{bp}+390 \mathrm{bp})$ and $\mathrm{XX}$ $(1.3 \mathrm{~kb})$

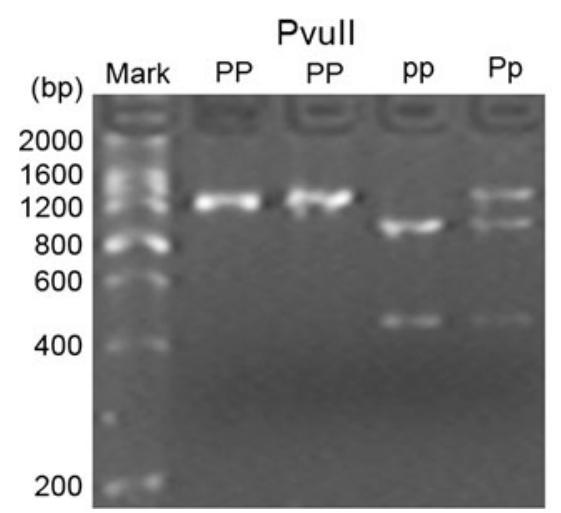

Table 4 The analysis of ER $\alpha$ Pvu II genotypes and allele frequencies

\begin{tabular}{|c|c|c|c|c|c|c|c|c|c|c|}
\hline \multirow[t]{2}{*}{ Groups } & \multicolumn{3}{|c|}{ PvuII restriction enzyme genotype (\%) } & \multicolumn{2}{|c|}{ Allele $(\%)$} & \multicolumn{3}{|c|}{ XbaI restriction enzyme genotype (\%) } & \multicolumn{2}{|c|}{ Allele (\%) } \\
\hline & PP & $\mathrm{Pp}$ & $\mathrm{pp}$ & $\mathrm{P}$ & $\mathrm{p}$ & $\mathrm{XX}$ & $\mathrm{Xx}$ & $\mathrm{xx}$ & $\mathrm{X}$ & $\mathrm{x}$ \\
\hline $\begin{array}{l}\text { Anxiety-depression } \\
\text { group }(n=78)\end{array}$ & $14(17.95)$ & $31(39.74)$ & $33(42.31)$ & 37.81 & 62.19 & $8(10.26)$ & $25(32.50)$ & $45(57.69)$ & 26.28 & 73.72 \\
\hline Control group $(n=72)$ & $15(20.83)$ & $34(47.22)$ & $23(31.90)$ & 44.44 & 55.56 & $11(15.27)$ & $26(36.11)$ & $35(48.61)$ & 33.33 & 66.67 \\
\hline
\end{tabular}

Using a Chi-square analysis, we found no significant differences between the two groups in the six genes $(\chi 2=0.66-1.65, P>0.05)$

\section{Discussion}

Our study shows that HARS-14, CHDS and Greene Climacteric Scale scores of anxiety, depression and somatic symptoms were significantly higher in perimenopausal/ postmenopausal patients with anxiety-depression disorder compared to a control group, whereas E2 and Progesterone levels were significantly lower $(P<0.01)$. These findings indicate that, in addition to anxiety and depression disorders, somatic symptoms are characteristics of climacteric patients with anxiety-depression disorders. This finding is also consistent with a previous report using Greene Climacteric Scale results $[25,26]$. Using a Pearson's correlation analysis, we found that a decreased E2 level is correlated with anxiety, depression and somatic symptoms, which in turn might be correlated with the onset of anxiety-depression disorder. Previous work by other researcher corroborates this finding [27, 28]. Additionally, our study indicates that anxiety, depression and somatic symptoms are correlated with psychological scores but not with blood pressure, bone density, menopause or disease course. These findings indicate the following: (1) the Greene Climacteric Scale is valid for determining climacteric patients with anxiety and depression disorders; and (2) the somatic symptoms in climacteric patients with anxiety-depression disorders might be correlated with emotional disorders only [28, 29] and not with organic diseases, such as hypertension and osteoporosis.

The anxiety-depression group showed a significant decrease in vasomotor symptoms, which is positively corre- lated with the HARS-14 score. This result is inconsistent with our other findings. Based on the symptoms of patients with anxiety-depression disorder, our study shows that there is correlation between vasomotor symptoms and the occurrence of anxiety disorders. Patients with light anxiety may keep their symptoms hidden, whereas patients with severe anxiety may show vasomotor. However, patients with anxiety-depression disorder showed a significant decrease in vasomotor symptoms, indicating that these symptoms may be characteristic of climacteric syndrome. Seritan and others have shown that vasomotor symptoms in patients with climacteric syndrome are closely associated with psychological status [28, 30]. Although we sampled patients with climacteric syndrome and anxiety-depression disorder, our results are consistent with previous findings. A recent report has shown that the somatic symptoms in climacteric syndrome might be the accumulative effect of anxiety and facial redness, which is also consistent with our observations [29].

Our study found a correlation between education level and anxiety and depression symptoms, indicating that people with more education are more likely to be anxious during menopause. This finding is inconsistent with the study by Kakkar et al. [1]. We did not find a significant change in sexual interest in the anxiety-depression group compared to the control group; this finding is also not consistent with the SWAN report. Asian attitudes toward sex-related issues tend to be conservative, which could explain our results. There seems to be no change in the sexual interest of patients with anxiety and depression. Moreover, our study 
indicated that sexual behavior is negatively correlated with depression scores, which is consistent with previous findings $[3,31]$.

The transcription factor of ER is located in the cytosol and nucleus and includes two isoforms: $\mathrm{ER} \alpha$ and $\mathrm{ER} \beta$. Human ER $\alpha$ is located on the 6q24-27 gene [8] and includes eight exons and seven introns, at a total length of $140 \mathrm{~kb}$. In the first ER $\alpha$ gene intron, we found a $\mathrm{T}$ to $\mathrm{C}$ mutation at $0.4 \mathrm{~kb}$ upstream of the second exon, and an $\mathrm{A}$ to $\mathrm{G}$ mutation $50 \mathrm{bp}$ downstream of the locus, resulting in the restriction sites for PvuII and XbaI, respectively, thus creating a restriction site polymorphism [8,9]. Previous studies have shown that the $\mathrm{ER} \alpha$ gene polymorphism is correlated with hot flashes and vaginal dryness but not with emotional disorders in patients with climacteric syndrome [32].

Our study indicates that the allele distribution of anxiety-depression genotypes is PP17.95\%, Pp39.74\%, $\mathrm{pp} 42.31 \%, \mathrm{XX10.26 \%}, \mathrm{Xx} 32.50 \%$ and $\mathrm{x} \times 57.69 \%$. The allele distribution frequency for the $\mathrm{P}$ and $\mathrm{X}$ alleles is 37.81 and $26.28 \%$, respectively. The majority of alleles are $\mathrm{p}$ and $\mathrm{x}$. Statistical analysis revealed no significant differences in the genotypes of the ER $\alpha$ PvuII and XbaI genes. Moreover, there was no correlation between the ER $\alpha$ allele and anxiety or depression symptoms. This finding is consistent with Malacara [32]. Based on a multifactorial logistic analysis, there is a negative relationship between the Pp genotype in the ER $\alpha$ gene and the C-MMSE score in the anxietydepression group $(r=-0.108, P=0.033)$.

Brandi et al. [8] showed that the PPXX genotype of ER $\alpha$ were more frequent in patients with Alzheimer's disease (AD), compared to a control group [8]. Estrogen level decrease is correlated to AD. Estrogen protects neurons. Estrogen therapy has positive effects on anxiety-depression disorder, cognitive malfunction and AD in patients with climacteric syndrome [33]. Depression related to aging may be a symptom of early-onset AD [8]. The SWAN report found that $18 \%$ of older women have emotional disorders and that depression was significantly correlated with impaired cognitive function [5]; however, there was no such correlation between emotional symptoms and cognitive malfunction in patients with climacteric syndrome [34]. In our study, we showed that anxiety, depression and somatic symptoms were negatively correlated with C-MMSE scores in the anxietydepression group; however, there was no such correlation in the control group. Thus, these findings are consistent with SWAN report which suggest cognitive decline correlation with anxiety and or depression, but not climacteric syndrome. There is a negative correlation between the Pp genotype in the ER $\alpha$ gene and C-MMSE scores, which is inconsistent with Olsen's report. In Olsen's study, the XbaI genotype XX was negatively correlated with impaired cognitive function in postmenopausal [35]. Recently, Kim et al.
[36] reported similar results. The inconsistent results may be relation to the difference of samples. Is there a correlation between impaired cognitive function of emotion disorder and the occurrence of mild cognitive impairment (e.g., MCI or early-onset $\mathrm{AD}$ )? Are the $\mathrm{ER} \alpha$ polymorphism and decreased estrogen levels common or different mechanisms in patients with climacteric syndrome as well as anxiety-depression disorders and patients with $\mathrm{AD}$ ? These questions need to be further investigated in perimenopausal/postmenopausal patients with anxiety-depression disorders.

\section{Conclusion}

The somatic symptoms in patients with climacteric syndrome are correlated with emotional disorders but not with organic diseases. There was no correlation between the $\mathrm{ER} \alpha$ allele polymorphism and anxiety or depression symptoms, whereas the Pp genotype of the ER $\alpha$ Pvu II gene may be related to impaired cognitive function in patients with anxiety or depression symptoms.

Acknowledgments This work was supported by the Natural Science Foundation of Guangdong Province, in China (06022385).

Conflict of interest The authors declare that they have no conflict of interest.

Open Access This article is distributed under the terms of the Creative Commons Attribution Noncommercial License which permits any noncommercial use, distribution, and reproduction in any medium, provided the original author(s) and source are credited.

\section{References}

1. Kakkar V, Kaur D, Chopra K, Kaur A, Kaur IP (2007) Assessment of the variation in menopausal symptoms with age, education and working/non-working status in north-Indian sub population using menopause rating scale (MRS). Maturitas 57:306-314

2. Soules MR, Sherman S, Parrott E et al (2001) Executive summary: Stages of Reproductive Aging Workshop (STRAW). Climacteric 4(4):267-272

3. Bromberger JT, Matthews KA, Schott LL, Brockwell S, Avis NE, Kravitz HM et al (2007) Depressive symptoms during the menopausal transition: the Study of Women's Health Across the Nation (SWAN). J Affect Disord 103:267-272

4. Clayton AH, Ninan PT (2010) Depression or menopause? Presentation and management of major depressive disorder in perimenopausal and postmenopausal women. Prim Care Companion J Clin Psychiatry. 12(1):PCC.08r00747

5. Colenda CC, Legault C, Rapp SR, DeBon MW, Hogan P, Wallace $\mathrm{R}$ et al (2010) Psychiatric disorders and cognitive dysfunction among older, postmenopausal women: results from the Women's Health Initiative Memory Study. Am J Geriatr Psychiatry 18(2): 177-186

6. Dowrick C, Katona C, Peveler R, Lloyd H (2005) Somatic symptoms and depression: diagnostic confusion and clinical neglect. $\mathrm{Br}$ J Gen Pract 55:829-830 
7. Rief W, Mewes R, Martin A, Glaesmer H, Braehler E (2010) Are psychological features useful in classifying patients with somatic symptoms? Psychosom Med 72:648-655

8. Brandi ML, Becherini L, Gennari L, Racchi M, Bianchetti A, Nacmias B et al (1999) Association of the estrogen receptor alpha gene polymorphisms with sporadic Alzheimer's disease. Biochem Biophys Res Commun 265:335-338

9. Herrington DM, Howard TD, Hawkins GA, Reboussin DM, Xu J, Zheng SL et al (2002) Estrogen-receptor polymorphisms and effects of estrogen replacement on high-density lipoprotein cholesterol in women with coronary disease. N Engl J Med 346:967-974

10. Kobayashi N, Fujino T, Shirogane T, Furuta I, Kobamatsu Y, Yaegashi $\mathrm{M}$ et al (2002) Estrogen receptor alpha polymorphism as a genetic marker for bone loss, vertebral fractures and susceptibility to estrogen. Maturitas 41:193-201

11. Ioannidis JP, Stavrou I, Trikalinos TA, Zois C, Brandi ML, Gennari L et al (2002) Association of polymorphisms of the estrogen receptor alpha gene with bone mineral density and fracture risk in women: a meta-analysis. J Bone Miner Res 17:2048-2060

12. Greene JG (2008) Constructing a standard climacteric scale. Maturitas 61:78-84

13. Cooper JE (1989) An overview of the prospective ICD-10 classification of mental disorders. Br J Psychiatry 154(Suppl 4):21-23

14. Zhang MY (1984) The Symptom Scales review. SHANGHAI JINGSHEN YIXUE Shanghai Arch Psychiatry, pp 261-264

15. Hamilton $\mathrm{M}$ (1959) The assessment of anxiety states by rating. $\mathrm{Br}$ J Med Psychol 32:50-55

16. Zheng YP, Zhao JP, Phillips M et al (1988) Validity and reliability of the Chinese Hamilton Depression Rating Scale. Br J Psychiatry 152:660-664

17. Stein DJ, Muller JCNS (2008) Spectr. Cognitive-affective neuroscience of somatization disorder and functional somatic syndromes: reconceptualizing the triad of depression-anxietysomatic symptoms 13(5):379-384

18. Chen RQ, Davis SR, Wong CM, Lam TH (2010) Validity and cultural equivalence of the standard Greene Climacteric Scale in Hong Kong. Menopause. 17(3):630-635

19. Mancia G, De Backer G, Dominiczak A, Cifkova R, Fagard R, Germano G et al (2007) 2007 ESH-ESC Practice Guidelines for the Management of Arterial Hypertension: ESH-ESC Task Force on the Management of Arterial Hypertension. J Hypertens 25:1751-1762

20. Cooper A (2009) Osteoporosis guideline. Br J Gen Pract 59:451

21. Kimber CM, Grimmer-Somers KA (2009) Multifaceted guideline implementation strategies improve early identification and management of osteoporosis. Aust Health Rev 33:423-433

22. Petersen RC, Stevens JC, Ganguli M, Tangalos EG, Cummings JL, DeKosky ST (2001) Practice parameter: early detection of dementia: mild cognitive impairment (an evidence-based review). Report of the Quality Standards Subcommittee of the American Academy of Neurology. Neurology 56:1133-1142
23. Zhang ZX, Hong X, Li H et al (1999) The Mini-Mental State Examination in population aged 55 years and over in urban and rural areas of Beijing. Zhonghua Shen Jing Ge Za Zhi. 32:149-153

24. Folstein MF, Folstein SE, McHugh PR (1975) "Mini-mental state". A practical method for grading the cognitive state of patients for the clinician. J Psychiatr Res 12:189-198

25. Sierra B, Hidalgo LA, Chedraui PA (2005) Measuring climacteric symptoms in an Ecuadorian population with the Greene Climacteric Scale. Maturitas 51:236-245

26. Travers C, O'Neill SM, King R, Battistutta D, Khoo SK (2005) Greene Climacteric Scale: norms in an Australian population in relation to age and menopausal status. Climacteric 8:56-62

27. Ryan J, Burger HG, Szoeke C, Lehert P, Ancelin ML, Henderson VW et al (2009) A prospective study of the association between endogenous hormones and depressive symptoms in postmenopausal women. Menopause 16:509-517

28. Seritan AL, Iosif AM, Park JH et al (2010) Self-reported anxiety, depressive, and vasomotor symptoms: a study of perimenopausal women presenting to a specialized midlife assessment center. Menopause 17:410-415

29. Lermer MA, Morra A, Moineddin R, Manson J, Blake J, Tierney MC (2011) Somatic and affective anxiety symptoms and menopausal hot flashes. Menopause 18:129-132

30. Gold EB, Colvin A, Avis N, Bromberger J, Greendale GA, Powell L et al (2006) Longitudinal analysis of the association between vasomotor symptoms and race/ethnicity across the menopausal transition: study of women's health across the nation. Am J Public Health 96:1226-1235

31. Katz-Bearnot S (2010) Menopause, depression, and loss of sexual desire: a psychodynamic contribution. J Am Acad Psychoanal Dyn Psychiatry 38:99-116

32. Malacara JM, Perez-Luque EL, Martinez-Garza S, Sanchez-Marin FJ (2004) The relationship of estrogen receptor-alpha polymorphism with symptoms and other characteristics in post-menopausal women. Maturitas 49:163-169

33. Sherwin BB, Henry JF (2008) Brain aging modulates the neuroprotective effects of estrogen on selective aspects of cognition in women: a critical review. Front Neuroendocrinol 29:88-113

34. Greendale GA, Wight RG, Huang MH et al (2010) Menopauseassociated symptoms and cognitive performance: results from the study of women's health across the nation. Am J Epidemiol 171:1214-1224

35. Olsen L, Rasmussen HB, Hansen T et al (2006) Estrogen receptor alpha and risk for cognitive impairment in postmenopausal women. Psychiatr Genet 16:85-88

36. Kim JJ, Pae CU, Kim MR et al (2010) Association between Estrogen Receptor Gene Polymorphisms and Depression in Post-Menopausal Women: A Preliminary Study. Psychiatry Investig 7(3):224-227 